Iğdır Üniversitesi Fen Bilimleri Enstitüsü Dergisi, 11(2): 927-932, 2021

Journal of the Institute of Science and Technology, 11(2): 927-932, 2021

Biology

ISSN: 2146-0574, eISSN: 2536-4618

DOI: 10.21597/jist.851610

Research Article

Received: 31-12-2020

Accepted: 17-02-2021

To Cite: Bezirganoglu I, 2021. Promoting effects of melatonin supplements on the embryogenic callus maintainance in alfalfa (Medicago sativa L.) Journal of the Institute of Science and Technology, 11(2): 927-932.

\title{
Promoting effects of melatonin supplements on the embryogenic callus maintainance in alfalfa (Medicago sativa L.) \\ İsmail BEZİRGANOGLU ${ }^{*}$
}

\begin{abstract}
The goal of this study was to determine melatonin impacts on the embryogenic callus formation and callus necrosis recovering of alfalfa (Medicago sativa L). Calluses, obtained from leaf explants, were cultivated on Murashige and Skoog (MS) medium supplemented with $0.0125 \mathrm{mg} \mathrm{mL}^{-1}$ melatonin $+1 \mathrm{mg} \mathrm{mL}^{-1} 2$,4-D or $0.0125 \mathrm{mg} \mathrm{mL}^{-1}$ kinetin $+1 \mathrm{mg} \mathrm{mL}^{-1}$ melatonin. Melatonin reduced the embryogenic callus formation in both concentrations. It was detected that the weight of fresh callus in genotypes was strongly related with hormones under in vitro conditions and the lowest fresh callus weight was detected in presence of $0.0125 \mathrm{mg} \mathrm{mL}^{-1}$ kinetin and $1 \mathrm{mg} \mathrm{mL}^{-1}$ melatonin. Based on the callus necrosis recovery, the highest callus necrosis weight $(0.843 \mathrm{~g})$ were recorded in embryogenic calluses cultivated in $0.0125 \mathrm{mg} \mathrm{mL}^{-1}$ melatonin $+1 \mathrm{mg} \mathrm{mL}^{-1}$ 2,4-D melatonin-supplemented medium, compared with the calluses activited with MS alone $(0.587 \mathrm{~g})$. In conclusion, it was detected in this study that in vitro melatonin could be used in callus necrosis recovered in tissue cultures of alfalfa.
\end{abstract}

Keywords: Melatonin, alfalfa, Embriyogenic callus, In vitro medium

${ }^{1}$ İsmail BEZiRGANOGLU (Orcid ID: 0000-0003-4079-5998), Erzurum Teknik Üniversitesi, Fen Fakültesi, Moleküler Biyoloji ve Genetik Bölümü, Erzurum, Türkiye

*Corresponding Author: İsmail BEZİRGANOGLU, e-mail: ismail.bezirganoglu@erzurum.edu.tr 


\section{INTRODUCTION}

Melatonin (N-acetyl-5-methoxytryptamine) is an indolic complex that has various functions in animals and plants. Melatonin has many significant biochemical roles in many plant species, where it seems to support an increasing plant's response to stress conditions. Many studies have been conducted and indicated a relationship between melatonin amount in cells and external environments (HernándezRuiz and Arnao 2008; Kim et al., 2016) The melatonin involves different physiological functions including ion absorption, nutrient transfer, gas exchange, stomatal balance, free radical scavenger and antioxidant (Erdal 2016; Murch and Saxena 2002; Reiter et al., 2002). Additionally, It also may act as a growth regulator and stimulate the formation of callus in vitro (Erland and Saxena 2017). It has previously been reported that alters in the basal levels of melatonin impact cell division and the formation of the mitotic spindle (Murch and Saxena 2002). The endogenous levels of melatonin influences various cytological processes including mitosis and the formation of the mitotic spindle (Murch and Saxena 2002; Turk et al., 2014). Although various impacts of melatonin in plants have been studied to date, studies about its impact on in vitro embryogenic callus maintaincae and plant regeneration are very limited. Moreover, to be able to increase callus formation and proliferate callus cultures in tissue cultures, suitable methods and growth regulators necessary to be developed and work efficiently. Not only is it needed to effectively induce and regeneration cultures, but also to efficiently synthesize compounds (Ullah et al., 2019). Nowadays, in vitro cultures have gained much importance compared to exogenous applications because of their to be a suitable and quick method to evaluate the quality and quantity of the melatonin and the other metabolites by stimulating the factors inducing their synthesis and/or accumulation. Alfalfa is the main forage crop for dairy producers of many agricultural regions due to its high feeding value. Alfalfa is cultivated for its high yield and potential for environment adaptation, wide disease tolerance, and nutritional feeding quality as well as its role on $\mathrm{N}$ fixation, wildlife habitat, soil conservation, and bioremediation (Pelagio-Flores et al., 2012; Hardeland et al., 2013). The medium components of tissue culture systems also play an main role in alfalfa in vitro culture. Leaf explants are well-known to be the best resources for efficient regeneration from callus cultures of alfalfa. The aims of this study was to determine the callus necrosis recover for alfalfa by investigating different melatonin concentrations embriyogenic callus medium.

\section{MATERIALS AND METHODS}

\section{Plant material and callus induction}

In our report, a cultivar and an ecotype (Sazova and $M u s$ ) were used as the material for the response to callus initiation. The mature seeds were sterilized with $22 \% \mathrm{NaOCl}$ for $20 \mathrm{~min}$, washed two times with autoclaved water. Coytledons or leaves were explanted to in vitro medium from two weeks old plants onto hormone-free MS medium (Murashige and Skoog 1962). For the melatonin treatment, cotyledons or leaves were explanted to in vitro medium containing MS basal medium ( $\mathrm{pH} 5.7$ ) and 0.8 $\%$ agar supplemented with $1 \mathrm{mg} \mathrm{mL}^{-1}$ of 2,4-D in the presence of $0.0125 \mathrm{mg} \mathrm{mL}^{-1}$ melatonin for a month. The callus were also obtained from leaf explants used for embryogenic callus initiation in the same melatonin concentration. The cotyledon and leaf explants were incubated in total darkness at $25 \pm 1{ }^{\circ} \mathrm{C}$ temperature for a month. After a month, callus formation was assessed and used for embriyogenic callus studies. 


\section{Embryogenic callus initiation and maintainance}

Callus was obtained from embryogenic callus initiation, such as control and melatonin treatment in terms of two different embryogenic callus maintaince medium. In the control treatment, intact callus were placed to the embryogenic callus initiation medium containing MS basal medium ( $\mathrm{pH} 5.7$ ) and 0.8 $\%$ agar supplemented with $1 \mathrm{mg} \mathrm{mL}^{-1}$ of 2,4-D and $0.0125 \mathrm{mg} \mathrm{mL}^{-1}$ of kinetin without melatonin for 1 months in a growth cabinet at $28^{\circ} \mathrm{C}$, under a $16 / 8$-h photoperiod condition. For the melatonin treatment, callus was transferred medium containing MS basal medium (pH 5.7) and $0.8 \%$ agar supplemented with $1 \mathrm{mg} \mathrm{mL}{ }^{-1}$ of 2,4-D in the presence of $0.0125 \mathrm{mg} \mathrm{mL}^{-1}$ melatonin for first medium. Callus was transferred medium containing MS basal medium ( $\mathrm{pH}$ 5.7) and $0.8 \%$ agar supplemented with 0.0125 $\mathrm{mg} \mathrm{mL} \mathrm{m}^{-1}$ of kinetin in the presence of $1 \mathrm{mg} \mathrm{mL}^{-1}$ melatonin for second medium. The callus were subcultured for each 3 weeks in the same medium. Total duration was 3 months. The embryogenic callus weight was evaluated at the end of 3 months.

\section{Statistical Analysis}

Each analysis was repeated three replicate. Analysis of variance was conducted using one-way ANOVA test using SPSS 13 software and means were evaluated by Duncan test at the 0.05 confidence level.

\section{RESULTS AND DISCUSSION}

\section{Embryogenic callus development capacity}

The fresh callus weight of Sazova and Muş genotypes was shown to reduce remarkably in response to melatonin treatment. Two different levels of melatonin were detected to cause great decreases in melatonin medium and the highest fresh callus weight was observed in all genotypes exposed to control treatments (Table 1). It was observed that the weight of fresh callus in genotypes was highly related with plant growth regulation under in vitro conditions and the lowest fresh callus weight was detected in presence of $0.0125 \mathrm{mg} \mathrm{mL}^{-1}$ kinetin and $1 \mathrm{mg} \mathrm{mL}-1$ melatonin (Table 1). Embryogenic callus development was influenced not only by genotype and plant gowth regulation but also by genotype $\times$ plant growth regulation interaction (Table 1). Among the two genotypes tested, 'Muş' $(1.414 \mathrm{~g})$ indicated the higher mean callus weight after 1 months incubation of the callus on the control media, followed by containing melatonin media but at same values both media whereas 'Sazova' (1.375 g) indicated the highest mean callus weight than $M u$ ş genotype after 1 months of incubation of the callus on control media, followed by 'Sazova' $(0.378 \mathrm{~g})$, after 2 months of incubation of the callus on $0.0125 \mathrm{mg} \mathrm{mL}^{-1}$ kinetin + media. Overall, the main impact of melatonin on embryogenic callus formation was not significant; however, embryogenic callus formation was significantly affected by melatonin concentration $(\mathrm{P}<0.05)$. Besides, there was no significant interaction between melatonin and dosages (Table 1).

\section{Effects of melatonin supplements on callus necrosis}

In terms of callus necrosis, two concentrations of melatonin were tested to provide the suitable concentration and times for healthy callus development. It was found that a combination of melatonin2,4-D had the tendency to decrease for callus necrosis of Sazova genotypes (Table 1). The calli produced at a combination of melatonin-2,4-D were compact, healthy, and fluffy whereas control callus was detected by black color and a watery appearance (Figure 1). The callus necrosis number of embryogenic callus was affected by the hormone concentration, type and their interaction. The callus necrosis of embryogenic callus ranged from $0.843 \mathrm{~g}$ to $0.032 \mathrm{~g}$ based on melatonin concentration and period (Table 1 ; Figure 2). 
Promoting effects of melatonin supplements on the embryogenic callus maintainance in alfalfa (Medicago sativa $\mathrm{L}$.)

Table 1. Changes in embryogenic callus maintaince in alfalfa genotypes combination auxin-melatonin

\begin{tabular}{|c|c|c|c|}
\hline Genotypes & Embryogenic callus weight (g) & Callus necrosis weight (g) & Fresh callus weight $(\mathrm{g})$ \\
\hline \multicolumn{4}{|l|}{ Months } \\
\hline \multicolumn{4}{|l|}{ 1.month of Sazova } \\
\hline Control & $1.375 \pm 0.059^{\mathrm{a}}$ & $0.587 \pm 0.019^{\mathrm{a}}$ & $0.787 \pm 0.036^{\mathrm{a}}$ \\
\hline Melatonin/2.4D & $0.291 \pm 0.059^{\mathrm{b}}$ & $0.843 \pm 0.019^{\mathrm{b}}$ & $0.231 \pm 0.036^{\mathrm{b}}$ \\
\hline Kinetin /melatonin & $0.202 \pm 0.059^{\mathrm{b}}$ & $0.091 \pm 0.019^{\mathrm{b}}$ & $0.110 \pm 0.036^{\mathrm{b}}$ \\
\hline \multicolumn{4}{|l|}{ 2. months of Sazova } \\
\hline Control & $0.320 \pm 0.075^{\mathrm{a}}$ & $0.063 \pm 0.042^{\mathrm{a}}$ & $0.239 \pm 0.031^{\mathrm{a}}$ \\
\hline Melatonin/2.4D & $0.221 \pm 0.075^{\mathrm{a}}$ & $0.055 \pm 0.042^{\mathrm{a}}$ & $0.199 \pm 0.031^{\mathrm{a}}$ \\
\hline Kinetin /melatonin & $0.378 \pm 0.075^{\mathrm{a}}$ & $0.152 \pm 0.042^{\mathrm{a}}$ & $0.259 \pm 0.031^{\mathrm{a}}$ \\
\hline \multicolumn{4}{|l|}{ 1.month of Muș } \\
\hline Control & $1.414 \pm 0.079^{\mathrm{a}}$ & $0.607 \pm 0.036^{\mathrm{a}}$ & $0.807 \pm 0.052^{\mathrm{a}}$ \\
\hline Melatonin/2.4D & $0.293 \pm 0.079^{\mathrm{b}}$ & $0.077 \pm 0.036^{\mathrm{b}}$ & $0.226 \pm 0.052^{\mathrm{b}}$ \\
\hline Kinetin /melatonin & $0.293 \pm 0.079^{\mathrm{b}}$ & $0.063 \pm 0.036^{\mathrm{b}}$ & $0.230 \pm 0.052^{\mathrm{b}}$ \\
\hline \multicolumn{4}{|l|}{ 2.months of Muş } \\
\hline Control & $0.258 \pm 0.036^{\mathrm{a}}$ & $0.041 \pm 0.012^{\mathrm{a}}$ & $0.807 \pm 0.024^{\mathrm{a}}$ \\
\hline Melatonin/2.4D & $0.131 \pm 0.036^{\mathrm{b}}$ & $0.055 \pm 0.012^{\mathrm{a}}$ & $0.076 \pm 0.024^{b}$ \\
\hline Kinetin /melatonin & $0.085 \pm 0.036^{\mathrm{b}}$ & $0.032 \pm 0.012^{\mathrm{a}}$ & $0.052 \pm 0.024^{b}$ \\
\hline
\end{tabular}

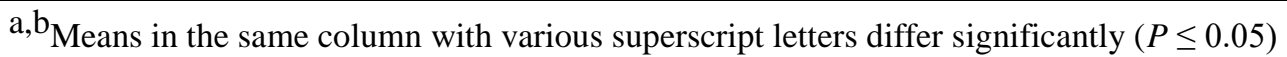
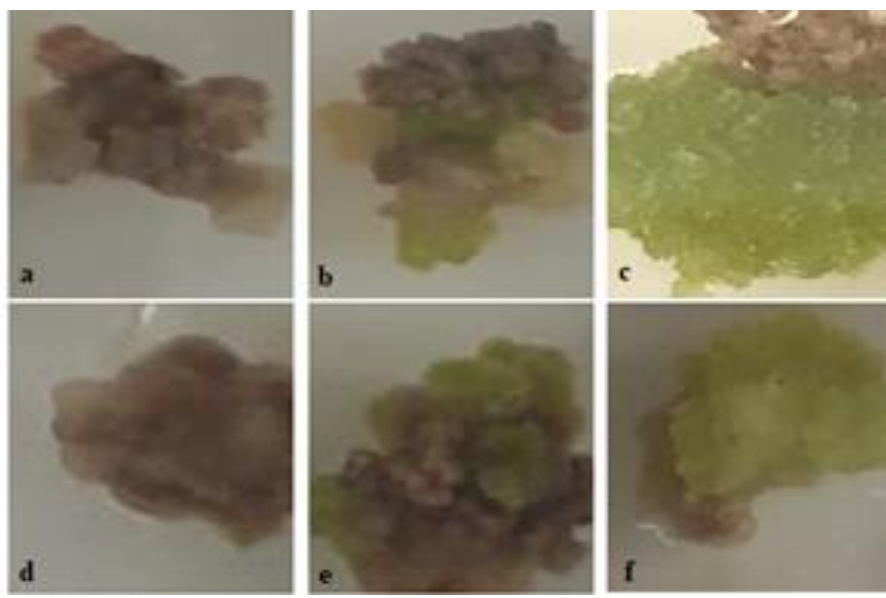

Figure 1: a: 2. Months of $M u s ̧$ control, b: $M u s ̧, 0,0125 \mathrm{mg} \mathrm{mL}^{-1}$ melatonin $+1 \mathrm{mg} \mathrm{mL}^{-1}$ 2,4-D c: $M u s ̧, 0,0125 \mathrm{mg} \mathrm{mL}^{-1}$ kinetin+ $1 \mathrm{mg} \mathrm{mL}{ }^{-1}$ melatonin d: 2 . months of Sazova control e: Sazova, 0,0125 mg mL $\mathrm{melatonin}^{-1} 1 \mathrm{mg} \mathrm{mL}^{-1} 2,4-\mathrm{D}$ f: Sazova, $0,0125 \mathrm{mg} \mathrm{mL}^{-1}$ kinetin+ $1 \mathrm{mg} \mathrm{mL}^{-1}$ melatonin

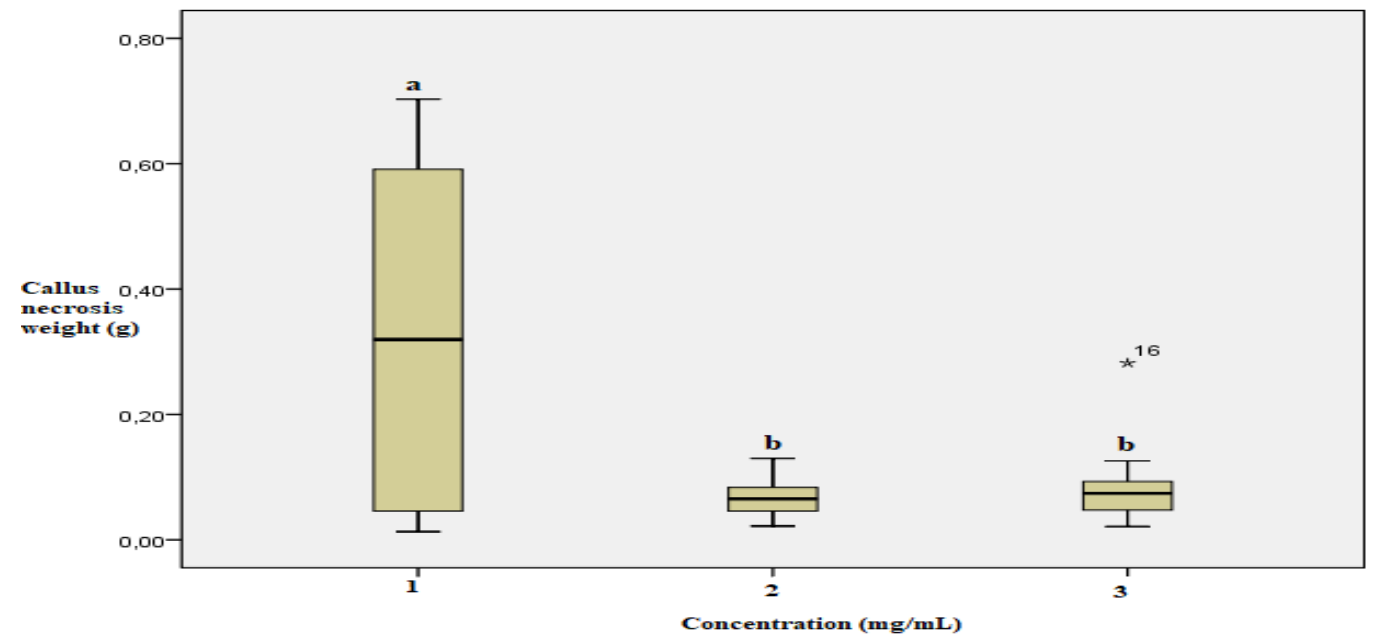

Figure 2: 1. control, 2. $0,0125 \mathrm{mg} \mathrm{mL}^{-1}$ melatonin $+1 \mathrm{mg} \mathrm{mL}^{-1} 2,4-\mathrm{D}$ 3. $0,0125 \mathrm{mg} \mathrm{mL}^{-1}$ kinetin+ $1 \mathrm{mg} \mathrm{mL}^{-1} \mathrm{melatonin}_{\text {. }}$

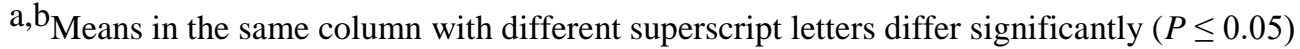


Despite the importance of alfalfa as a forage plant, the research on this plant is difficult due to allogamy, perennial and cross-fertilization as well as polyploidy (Şakiroğlu et al., 2010). Therefore the application of in vitro technique can be useful for genetic improving of alfalfa. The culture medium optimization can be affected by many traits, such as explant sources, genotype, growth conditions and medium composition (Yazicilar et al., 2021). The combination of cytokinins and auxins promoted callus induction in a number plant species (Chaudhry et al., 2014). Melatonin has been demonstrated as playing a main functions in callus induction and somatic embryogenesis. The impacts of melatonin on in vitro culture have been studied by several researchers (Chaudhry et al., 2014), who proposed that melatonin activity as hormone regulators of callus formation. Ramakrishna et al., (2011, 2012) showed that melatonin has an promoted impact during the late stages of embryogenic callus growth in terms of the number of somatic embryos in Coffea canephora. It was found that melatonin treatment promoted responded callus necrosis rate in short-term period and embryogenic callus efficiency during long-term period in our study (Table 1). Our results are in consistent with those published by Duran et al., (2019) in the study on Ocimum basilicum the addition of melatonin at $100.0 \mu \mathrm{M}$ and $200.0 \mu \mathrm{M}$ dosages in the tissue culture medium. Their results demonstrate that melatonin reduced the frequency of callus formation compared with the control medium without melatonin. However, at $100.0 \mu \mathrm{M}$ of melatonin in the medium, the differentiation frequency of adventitious buds from callus appeared to increase. This can be explained that callus formation is strongly related to hormone combination and concentration. According to our results, increases in necrosis recovering in melatonin-treated callus may be related to synergistic role of melatonin as direct or indirect due to was found to inhibit or promote callus necrosis and embryogenic callus formation dependent genotypes (Figure 2). Similar observations were also obtained in Hypericum perforatum L. (Murch et al,. 2001), Punica granatum L. (Sarrou et al., 2014), A. thaliana (Koyama et al., 2013), and Withania somnifera (L.) Dunal (Adil et al., 2015). For example: 1 $\mu \mathrm{M}$ melatonin application in cherry considerably inhibit the promotion effects of in vitro culture, whereas $8.6 \mu \mathrm{M}$ melatonin still found a enhancing effect in P. Granatum.

\section{CONCLUSION}

Herein, we showed that melatonin can be used as a good auxin-cytokinin for the callus and embryogenic tissue culture. Moreover, It was detected in this study that in vitro melatonin could be used in callus necrosis recovered in tissue cultures of alfalfa. Besides it is still necessary for suitable hormone concentration requiring more detailed studies.

\section{Conflict of Interest}

I declare that there is no conflict of interest during the planning, execution and writing of the article.

\section{Author's Contiibutions}

I hereby declare that the planning, execution and writing of the article was done by me as the sole author of the article.

\section{REFERENCES}

Adil M, Abbasi BH, Khan T, 2015. Interactive effects of melatonin and light on growth parameters and biochemical markers in adventitious roots of Withania somnifera L. Plant Cell Tissue Organ Cult, 123: 405-412.

Chaudhary D P, Jat S L, Kumar A, Kumar B, 2014. Fodder quality of maize 1ts preservation. Springer India, 153160. 
Erdal S, Turk H, 2016. Cysteine-induced upregulation of nitrogen metabolism-related genes and enzyme activities enhance tolerance of maize seedlings to cadmium stress. Environ Exper Bot, 132:92-99.

Erland LAE, Saxena PK, Murch SJ, 2017. Melatonin in plant signalling and behaviour. Funct Plant Biol, https://doi.org/10.1071/FP16384.

Hardeland R, 2013. Melatonin and the theories of aging a critical appraisal of melatonin's role in antiaging mechanisms. J Pineal Res, 55:325-356.

Hernández-Ruiz J, Arnao MB, 2008. Melatonin stimulates the expansion of etiolated lupin cotyledons. Plant Growth Regul, 55:29-34.

Kim M, Seo H, Park C, Park WJ, 2016. Examination of the auxin hypothesis of phytomelatonin action in classical auxin assay systems in maize. J Plant Physiol, 190:67-71.

Koyama FC, Carvalho TLG, Alves E, da Silva HB, de Azevedo MF, Hemerly AS, Garcia CRS, 2013. The structurally related auxin and melatonin tryptophan-derivatives and their roles in Arabidopsis thaliana and in the human malaria parasite Plasmodium falciparum. J Eukaryot Microbiol, 60:646-651.

Murashige T, and F A Skoog, 1962. A revised medium for rapid growth and bioassays with tobacco tissue cultures. Plant Physiology, 15: 473-97.

Murch SJ, Campbell SSB, Saxena PK, 2001. The role of serotonin and melatonin in plant morphogenesis regulation of auxin-induced root organogenesis in in vitro-cultured explants of St. John's wort (Hypericum perforatum L.) In Vitro Cell Dev Biol Plant, 37:786-793.

Murch SJ, Saxena PK, 2002. Mammalian neurohormones potential significance in reproductive physiology of St. John's wort (Hypericum perforatum L.)? Naturwissenschaften, 89:555-560.

Pelagio-Flores R, Muñoz-Parra E, Ortíz-Castro R, López-Bucio J, 2012. Melatonin regulates Arabidopsis root system architecture likely acting independently of auxin signaling. J Pineal Res, 53:279-288.

Ramakrishna A, Giridhar P, Jobin M, Paulose CS, Ravishankar GA, 2011. Indoleamines and calcium enhance somatic embryogenesis in Coffea canephora Pex Fr. Plant Cell Tissue Organ Cult, 108:267- 278.

Ramakrishna A, Giridhar P, Sankar KU, Ravishankar GA, 2012. Endogenous profiles of indoleamines serotonin and melatonin in different tissues of Coffea canephora Pex Fr. As analyzed by HPLC and LC-MS-ESI. Acta Physiol Plant, 34:393-396.

Reiter RJ, Tan DX, 2002. Melatonin an antioxidant in edible plants. Ann N YAcad Sci, 957:341-344.

Sakiroglu M., JJ Doyle, EC Brummer, 2010. Inferring population structure and genetic diversity of broad range of wild diploid alfalfa (Medicago sativa L.) accessions using SSR markers. Theor Appl Genet, 121:403415.

Sarrou E, Therios I, Dimassi-Theriou K, 2014. Melatonin and other factors that promote rooting and sprouting of shoot cuttings in Punica granatum cv. Wonderful. Turk J Botany, 38:293-301.

Turk H, Erdal S, Genisel M, Atici O, Demir Y, Yanmis D, 2014. The regulatory efect of melatonin on physiological, biochemical and molecular parameters in cold-stressed wheat seedlings. Plant Growth Regul, 74:139-152.

Ullah M.A, Tungmunnithum D, Garros L, Drouet S, Hano C, Abbasi BH, 2019. Effect of Ultraviolet-C Radiation and Melatonin Stress on Biosynthesis of Antioxidant and Antidiabetic Metabolites Produced in In Vitro Callus Cultures of Lepidium sativum L. Int. J Mol Sci, 20:1787.

Yazıcılar Y, Böke F, Alaylı A, Nadaroğlu H, Gedikli S, Bezirganoğlu I, 2021. In vitro effects of $\mathrm{CaO}$ nanoparticles on Triticale callus exposed to short and long-term salt stress. Plant Cell Report, 40:29-42. 